\title{
Duas vezes \\ Maria Filomena Molder
}

\section{Pedro Fernandes Galé Universidade Federal de São Carlos | São Paulo | Brasil}

Maria Filomena Molder (2014), As nuvens e o vaso sagrado, Lisboa: Relógio D’Água.

Maria Filomena Molder (2017), Dia alegre, dia pensante, dias fatais, Lisboa: Relógio D’Água.

É necessário conhecer o próprio abismo E polir sempre o candelabro que o esclarece.

Murilo Mendes, Poema Dialético

Comecemos por observar que o público de filosofia no Brasil deve celebrar o fato de a obra de Maria Filomena Molder, filósofa e ensaísta portuguesa, ter sido escrita em nossa língua. Embora tenhamos um Atlântico e seus gigantes entre nós, a leitura destes livros, um deles, As nuvens e o vaso sagrado, surgido em 20I4, o outro, Dia alegre, dia pensante, dias fatais, de 2017, apresenta-nos como que a essencialidade de nossa língua, em seus obstáculos e suas riquezas, diante de objetos que têm sua origem alhures. É para a nossa língua mãe que Filomena Molder arrasta grandes questôes, grandes pensadores, grandes poetas que perambulam no mundo multilíngue. Sob sua pena, a filosofia e a poesia ganham uma verve lusófona, na qual notamos a unidade em meio à variedade. Não se trata de uma germanista, mas de uma irmã em letras e filosofia germânicas (quando o caso) em bom português.

Mais do que a unidade dada a reboque pelo fato de serem ambos da mesma autora, há entre os dois livros aqui resenhados uma unidade de caráter, que se apresenta inicialmente em termos formais; pois, em ambos, o que temos é uma série de ensaios que buscam a sua unidade no "amálgama, no sentido goethiano (alquímico), de preferência” (Molder, 20I7, p. I2). Isso não significa que tenhamos um trabalho disforme e errático. A unidade se apresenta ao leitor como um 
lume que percorre as linhas dessas obras; uma chama que perpassa os textos sem deixar de chamar para o diálogo toda uma tradição que une poetas e filósofos em suas indagações mais específicas.

Se As nuvens e o vaso sagrado é um livro de construção elíptica, tendo por focos Kant e Goethe, Dia alegre, dia pensante, dias fatais gira em torno de uma miríade de temas aos quais a herança filosófica vem fazer coro; coro nem sempre consonante e que por vezes se constrói a partir da própria dissonância. Nesses dois livros são apresentadas duas faces do trabalho de Filomena Molder; vemos ecoar os esforços da autora da obra $O$ pensamento morfológico de Goethe (Imprensa Nacional; Casa da Moeda, Lisboa, 1995), obra que se tornou uma referência nos estudos de Goethe, bem como a singular obra Matérias sensiveis (Relógio D’Agua, 1999), onde autores como Walter Benjamim e Baudelaire dividem espaço com estudos e observações de obras e artistas do quilate do artista plástico português Jorge Martins. O trabalho marcado pelo rigor filosófico ganha como aliado o ofício crítico mais presencial.

Nas duas publicações mais recentes sentimos ressoar a carga peculiar de seu trabalho de Professora universitária e de crítica de arte. A forma ensaística não traz nada de orbívago e impreciso, oferece um encerramento que se deixa abrir, que estende suas inquietaçôes para o que há de mais banal e ao mesmo tempo insolúvel no ato de escrever e de pensar. Nos textos dos volumes que aqui comentamos unem-se a agitação do neófito e o rigor da longa experiência. Os textos parecem fazer uma espécie de profissão de fé, que lança os seus dardos a qualquer sorte de caracterização inerte dos assuntos que movem a Professora de estética da Universidade Nova de Lisboa.

Em tempos onde a especialização também em filosofia torna-se cada vez mais precoce e irreversível é uma grata satisfação deparar-se com obras como as que tratamos aqui. Numa abordagem em que "as leituras se fazem por coagulação, sem plano prévio" (Molder, 20I4, p. II), o preciosismo dá lugar a preciosidades. Longe de se apresentar como que caoticamente orgânico, o situar-se diante das questôes e dos autores que se pretende tratar traz a marca de uma unidade que perpassa o tom que visa o literário aliado à precisão. Vemos ganhar corpo um trajeto (de décadas) que se fez por "atração e irradiação" (Ibid.), que se consolida por movimentos precisos.

Sem ceder a qualquer sorte de disputa ou de Parangone, que tanto entusiasma leitores propensos a diagnósticos de época, os ensaios de Filomena Molder não deixam de buscar o espírito conciliador em seus leitores, uma conciliação que é ao mesmo tempo desafiadora e irresistível. A autora parece se confrontar com seu tempo e com a herança dos séculos que nos antecedem recusando-se a nomenclatura do contemporâneo: "Enquanto conceito da história e da crítica de 
arte, 'contemporâneo' parece não só por termo à natureza histórica dos conceitos a que imediatamente se sucede: antigo, moderno, pós-moderno, como também fechar a porta a um que venha depois. Neste quadro há lugar a uma pergunta: os artistas veem-se como contemporâneos?" (Molder, 20I7, p. I63).

No prefácio de As nuvens e o vaso sagrado, uma espécie de justificativa da empresa filosófica de Filomena Molder, observamos uma recusa que, se não é exclusiva, é bastante rara:

Por estranho que pareça, resistia, sempre que alguém ficava a par dos autores (na sua maioria) sobre os quais costumava escrever e me qualificava com um 'Ah, é germanista!' E porquê? À míngua de outras razões que se adiantem, há uma que vem imediatamente ter comigo: é porque escrevo em português e só em português consigo pensar e falar. Mesmo cometendo erro, com todos os perigos associados, desproporção e incomensurabilidade, o que me importa é ver como fica, pensando eu sempre em português, aquilo que outro disse em língua alemã (ou outra, conforme). Isto sem que me pusesse a observar essa tradução, essa transição a fazer-se, movendo-me desde o início dentro dela, numa procura de identidade por caminhos que não vão a direto (Molder, 20I4, p. I3).

Vemos, de modo inconteste, que ainda que se pense a português em torno de autores de outra língua, é no vernáculo materno que a matéria ganha nova forma e novas consequências. Trata-se de um feliz acontecimento que em nossa língua surjam obras que, graças à característica própria da lusofonia, oferecem novos modos de leitura de autores cuja fortuna crítica é tão ampla quanto irregular. Não se trata de emular a língua de origem de seu paideuma, mas de verter para o português operações de pensamento que se metamorfoseiam pela transposição linguística, produzindo novas consequências e ressonâncias.

No âmbito do livro As nuvens e o vaso sagrado é nessa transposição feliz, que não busca uma internacionalização irrestrita, que a autora mostra que está a combater certas restriçôes que se colocam ao que busca estudar a obra desses dois grandes vultos da cultura de língua alemã, Goethe e Kant. Filomena Molder parece restaurar e atualizar um aspecto da recepção de Kant que guarda bastante analogia com Goethe, que, diante da excitação ocasionada pela publicação da Crítica do juizo, escrevera o seguinte:

Excitado apaixonadamente, continuava pelo mesmo caminho, só que cada vez mais rapidamente, porque eu próprio não sabia até onde ele me conduzia, e o meio e o modo como me tinha apropriado encontrava fraco acolhimento entre os kantianos. [...] Nem sempre consegui aproximar- 
-me dos kantianos; eles escutavam-me, mas não podiam replicar sem ser, de algum modo, benéficos (Goethe, 1993, p. 66).

A autora parece instalar-se na mesma esteira, pois por meio de uma apropriação busca "extrair da parte estética da terceira crítica tudo que pudesse justificar o combate para dissolver a fixação de um cânone kantiano" (Molder, 20I4, p. I2). A tarefa aqui, ao modo de Goethe, é a de "observar os pontos problemáticos que dificultassem o preenchimento do impulso sistemático, próprio de Kant: eis o que aprendi com o dragão, contra ele mesmo." (Ibid.). Temos de ter em mente, desde o prefácio deste livro, que a centralidade dos dois autores a serem tratados, Kant e Goethe, não se dá de modo excludente ou isolado. Ambos parecem, e mais uma vez a analogia com Goethe é clara, "iluminarem-se alternadamente [...]. As produções desses dois mundos infinitos deviam existir autonomamente e o que estava ao lado de um do outro estava absolutamente um para o outro, mas não intencionalmente um por causa do outro." (Goethe, 1993, p. 66).

Os textos que se seguem, atrelados aos seus dois focos, nos revelam o quanto esses autores se refletiram e se refrataram. Superando até mesmo a limitação da elipse formada por eles, não deixam de iluminarem-se mutuamente o poético e o filosófico, de certa forma simbolizados por esses mesmos autores, ou ainda, procedimentos que veem contrair e expandir nos textos do livro. É nesse expediente alternado que vemos a clara dimensão de proximidade entre a palavra e o mundo: "As palavras do filósofo nomeiam de tal modo a coisa que o ocupa que ela parece ser descoberta nesse mesmo ato, como se a paisagem fosse pela primeira vez reconhecida. É isto! Esse quinhão partilha-o com o poeta e com o artista." (Molder, 20I4, p. 23). Não deixa de ser um alento, nesses tempos indigentes (como na conhecida imagem de Hölderlin), que se possa, não sem atrevimento, colocar lado a lado as demandas artísticas e as demandas filosóficas. Em tempos onde a tecnicidade solapou a sensibilidade no trato com os textos clássicos, até mesmo na disciplina filosófica da estética, é de grande valor que se possa ainda ler passagens como a seguinte:

Assim como as nuvens de Stieglitz, os céus de Tiepolo ou de Turner, os pícaros e as garrafas de Morandi, o coiote e as ardósias de Beuys, há a voz universal de Kant. Modos de ver e ouvir que passam a enlear os nossos olhos e a compreensão, que permitem, redimem e reconciliam as inquietas passagens entre o visível e o invisível. (Ibid.)

Nessas passagens, Filomena Molder parece tomar para si a missão de conciliar contrários (retomando a imagem pela qual Manuel Bandeira se referia a Murilo Mendes). Sem que a força de uma forja ou molde se faça necessária, tudo se dá 
num movimento contínuo de uma busca por acordos e proximidades que não se apresenta por uma confusão entre limites.

Que não confundamos o duplo foco com um barateamento das questões, não se trata de ler Kant como poeta e muito menos de torturar o autor do Fausto até que se confesse filósofo. A leitura de ambos não é em nada superficial, o livro encontra belos momentos de um corpo a corpo com os textos que faz o leitor ganhar um repertório que, se não é novo, se faz intensificar e gerar novos frutos. Para não mais que ilustrar o trato com os autores, nesse caso Kant, que nos baste uma citação (longa é verdade) do ensaio "O juízo estético em Kant como educação sentimental":

Anteriormente à Crítica da faculdade de julgar, encontramos o conceito de reflexão quer na "Anfibolia dos conceitos da reflexão", da Crítica da razão pura quer nos $\$ \$ 5$ e 6 da Lógica de Jäsche. [...] Na "Anfibolia", Kant desenvolve ainda uma vez mais o seu motivo central da heterogeneidade entre a sensibilidade e o entendimento. Em contrapartida, na Crítica da faculdade de julgar, ele [Kant] faz-nos conhecer uma profusão de comparaçōes, como uma fuga a várias vozes. No que diz respeito ao juízo estético, podemos reconhecer três círculos comparativos inseparáveis e que se interpenetram: o Gemüt compara-se com a representação e, nessa ocasião, toma posse sentimental de si $(\$ \mathrm{I})$; por outro lado, por meio de um jogo comparativo entre a imaginação e o entendimento, revela-se como livre contemplação, como acordo vivo e harmónico, aquilo que o conceito de "elemento subjectivo" [das Subjektive] dá conta (Introdução VII, $\$ \$ 35$ e 38); finalmente, descobre a sua pertença a uma comunidade pela comparação com cada um dos outros, tentando colocar-se no seu lugar. No $\$ 40$, Kant não poderia ser mais claro no que diz respeito ao reenvio do sensus communis a um princípio de comparação. Para o filósofo, trata-se de um verdadeiro guia sentimental para o reino ético, uma pura propedêutica: a comunidade humana prepara a comunidade racional (Molder, 20I4, p. IOI).

É com esse espírito arqueológico que a autora vai escavar os escritos dos autores de que trata no livro. Em Goethe, não vai deixar de lançar novas tarefas de compreensão àquele que busca adentrar o corpo da obra do grande poeta alemão; em nome de certo equilíbrio citamos aqui uma passagem do texto "Por que razão seremos, nós, Modernos, tão dispersos?", onde a heurística viva, de Goethe, é abordada:

Todas as investigações devem realizar-se de tal modo que seja possível um movimento de regresso àquilo mesmo que se observa, devolvendo-lhe sua verdadeira fisionomia, conseguindo alcançar uma síntese elevada, 
aquela que se avizinha da perfeição de um ser vivo. Acentuar temerariamente a análise ou temer excessivamente a síntese impede-se que se caminhe o bom caminho. 'por que só ambas em conjunto, como expiração e inspiração, constituem a vida da ciência'. Não é possível qualquer afinidade com a constituição do conhecimento própria da Crítica da Razão Pura (Molder, 2014, p. 67).

Para facilitar a transição entre os dois volumes, tomemos como entrada nesse Dia alegre, dia pensante, dias fatais a passagem do texto "A escada, o raio e a serpente", onde Maria Filomena Molder parece indicar uma partilha intelectual entre Goethe e Warburg, sobre algumas passagens do Schlangenritual. Ela escreve: "É uma evidência que Warburg ama a polaridade, isto é, as oposições que não conhecem síntese que as absorva ou supere. Goethe foi, entre os alemães, não só o instigador desta espécie de pensamento, como aquele que a desenrolou" (Molder, 20I7, p. 4I). É na destreza de se encaminhar por entre dualidades que os textos ordenados sob a amálgama da preferência vão apresentando um rico panteão de contribuiçôes de leitura que tratam de questôes e procedimentos que apresentam autores e saberes em um complexo que busca no leitor o fio de Ariadne.

Um aspecto que salta à vista nesse volume é a condição da própria história. Contemporâneos até mesmo de nossos mais longínquos antepassados, nós leitores, temos de pensar que a história, "trata com cinzas, restos funerários, e não é possível pôr entre parêntesis dominância desse elemento catastrófico" (Ibid., p. 42). É entre os artistas que esses conceitos históricos parecem se arrefecer, pois "os conceitos históricos não lhes convêm, sobretudo se esses conceitos são engendrados pelo mundo da arte, e dos seus mercados, no qual, quer queiram ou não queiram, os artistas fazem sempre o papel de exilados [...] Os poetas são mais livres, o mercado quase não lhes consegue meter os dentes” (Molder, 20I7, p. I64).

É entre artistas, poetas, filósofos e historiadores que a cadeia se volta não para os temas desenvolvidos, mas por uma unidade excêntrica e extrínseca fornecida pelos textos reunidos. Das cinzas de um passado do qual somos contemporâneos, surgem os contemporâneos deste passado e é assim que o mar de Homero, em sua Odisseia (o mar cor de violeta), se vê confrontado com o mar salgado de Pessoa (Quanto de teu sal / São lágrimas de Portugal). Não que isso implique em uma unidade que ignore o abismo cavado entre o antigo e o moderno, mas é no comparativo que se reabrem os contrastes e se delineiam as formações deste abismo: "Entre a existência pura, nua, que é o mar, e o abismo humano, há um vínculo que não é observável entre os gregos (de Homero à tragédia)" (Ibid., p. 3I).

O mar como metáfora, como linguagem, como condição abre o bloco de textos dedicados à linguagem. Num registro singular, Filomena Molder parece, como esteta e como investigadora de filosofia, retomar a imagem de reconciliadora 
de contrários. Se é sobre a linguagem que repousam boa parte das linhas deste volume, é também por uma espécie de recurso às dualidades que as operações do espírito, expostas em linguagem se vão desenvolvendo. Desde o primeiro texto do livro, onde a luz e a escuridão, dia e noite, parecem indicar um dilaceramento, as dualidades se vão multiplicando "polaridades, cuja pertença recíproca não pode ser erradicada" (Molder, 20I7, p. 4I). Entre o dizível e o indizível a linguagem se constrói no sentido de "que as palavras não são as coisas e nem tudo que se sabe pode ser dito" (Ibid., p. 7I).

É nessa toada que filosofia da linguagem e poesia se vão encontrando e ganhando sua manifestação, enquanto contrapartes, até a manifestação mais clara dessa dissonância que ressoa em uníssono nos dois episódios de "Confissão de uma estranheza", onde é manifesta a tendência ao plural: "Pensamentos no plural também é bom, pois o sopro da vida gosta dos muitos e dos vários, "mais vale uma pedra e um anjo do que dois anjos'. São Tomás dixit e nós aplaudimos” (Ibid., p. 65). Poesia e filosofia, o anjo e a pedra vão ganhando as páginas que nos fazem avolumar inquietações e estranhezas. É numa leitura que Wittgenstein fez de Kleist que inicia-se o primeiro episódio que nos leva a pensar a linguagem como que a serviço do sopro da vida e até mesmo do corpo, onde "ler é uma espécie de respiração boca a boca" (Ibid.). Filomena Molder chega mesmo, por meio de uma série de leituras do filósofo de Viena, a indicar uma libertação da linguagem que levaria aos "incontáveis usos que fazemos das palavras e a rede viva que tecem" (Ibid.).

Depois de ensaiar, com destreza em torno da linguagem vemos o livro voltar-se ao poético, e é no âmbito do pensamento em torno da poesia que temos uma notável gama de possibilidades e dualidades que se apresentam num tom que beira ele mesmo o poético. Aqui entra a poesia que se recusa a ser consumida como literatura; uma existência do poético ciente do abismo que sua própria condição abriga. O poema ganha o estatuto central, já acenado pelos ensaios anteriores, no texto que dá nome ao volume "Dia alegre, dia pensante, dias fatais". Ao deitar os olhos sobre Hölderlin, a Filomena Molder, não vai se investir das leituras clássicas, embora o mote seja trazido por Benjamim, em um escrito inédito intitulado dois poemas de Hölderlin, a leitura aqui avança entre dualidades que caracterizam o ofício poético e as estruturas da poesia: "O mito é condição constitutiva do poema, a sua coesão externa, a ardência de uns aos outros, a compenetração de uns pelos outros, dos seus elementos constitutivos originais. Mito é a unidade que não pode ser descrita, mas na qual se tem de abrir uma brecha para tornar legível o poema” (Molder, 20I7, p. 93).

Sabedora da condição clássica da questão, e da retomada, em terras alemãs, da mitologia e da filosofia da mitologia, a autora parece querer resolver o impasse 
apresentando o mitológico como algo que "já faz parte da ordem da cultura, da transmissão" (Ibid., p. 94) a mitologia não é um recurso, o poema pertence a esta ordem, e também não é algo que acena de um monumental passado, a mitologia percorre todo o poema que se pretende poético, é na afinidade com o mítico que o poetizado se vai expressar, mas não se deve confundir a ambos.

Como esta resenha não pretende esgotar os diversos ensaios do livro, basta por ora, diante dessa obra de caráter "irresenhável" que se diga que mesmo diante de Herberto Helder, para quem são dedicadas algumas das mais belas páginas, ou de Wittgenstein, figura recorrente entre suas linhas, o poético e o teórico parecem se confundir e relançar o leitor ao campo irrestrito poesia e da filosofia, como se ambas se iluminassem mutuamente. A linguagem, aqui empreendida não como veículo, mas como corpo e apresentação da própria dualidade. $\mathrm{O}$ livro parece se estabelecer num caos, mas num caos "que supõe uma pré-configuração, uma pré-legislação prestes a dar-se a conhecer” (Ibid., p. 96). E nesse sentido a leitura do livro é um exercício contínuo de refazer uma missão da poesia, a saber, buscar incitar "caos à disciplina” (Ibid.). Sem lançar mão de qualquer sorte de sucateamento do rigor filosófico ou submeter a poesia a uma sorte de estratagema crítico que a sufoque, Filomena Molder sabe que "a obra é mais decisiva do que a atenção que lhe é dedicada, melhor, esta atenção responde a um apelo e a um constrangimento da obra, e a sua plenitude, a sua fertilidade, depende do tomar a obra como lugar de obediência, de revelação da essência e da existência do ser Humano." (Ibid., p. 78).

\section{Referências}

Goethe, J. W. (1993). A metamorfose das plantas, tradução e organização de Maria Filomena Molder, Lisboa: Imprensa Nacional.

Molder, Maria Filomena (20I4), As nuvens e o vaso sagrado, Lisboa: Relógio D’Água.

Molder, Maria Filomena (2017), Dia alegre, dia pensante, dias fatais, Lisboa: Relógio D’Água. 